\title{
Exploration of Social-economic and Environmental Impacts on Lung Cancer Mortality in 94 Countries With Artificial Neural Network and Random Decision Tree Analysis
}

Xiu Wu

Texas State University

Jinting Zhang ( $\nabla$ whuzjt@whu.edu.cn )

Wuhan University

Blanchard-Boehm Denise

Texas State University

\section{Research Article}

Keywords: Lung Cancer Mortality, Artificial Neural Network, Random Decision Tree, Spatial-temporal Analysis

Posted Date: December 20th, 2021

DOl: https://doi.org/10.21203/rs.3.rs-1167346/v1

License: (c) This work is licensed under a Creative Commons Attribution 4.0 International License. Read Full License 


\section{Abstract}

\section{Background}

Since lung cancer is the biggest killer in cancer families, extremely threatening to human health, an understanding of social-economic and environmental impacts on lung cancer mortality (LCM) is imperative to improve patient psychological health and potentially mitigate lung cancer incidences and multimorbidity. Figuring out key indicators in social-economic and environment impacts which are sensitive to LCM on spatial-temporal scales contributes to preclinical control and systemic treatments for lung cancer with standard chemotherapy agents are still relatively ineffective.

\section{Methods}

Based on lung cancer mortalities in 94 countries within a decade (2006-2016), this research appropriately dissects social-economic, demographic, and environmental independent variable effects using Artificial Neural Network (ANN) and CRT Random Decision Tree algorithms (CRT-CRT-RDF).

\section{Results}

With the two methods comparison, the similarity is that education and carbon emission were two etiologies. Education in low and middle countries of lung cancer was related with total ecological footprint and total population. Carbon emission in extreme countries was linked to ecological forestland footprint. Spatial-temporal analysis postulated China and the U.S were the two largest countries whereas China and India were the two fastest countries of LCM growth. Both models have a high precision of prediction ( $96.1 \%$ of CRT-CRT-RDF and $98.4 \%$ of ANN).

\section{Conclusions}

This research will facilitate preventive lung cancer services, prioritize the geographical allocation of lung cancer investment for $\mathrm{WHO}$, and provide evidence for shrinking carbon emission and deforestation.

\section{Introduction}

Lung cancer is increasingly common as a second primary malignancy. It was defined using the International Classification of Diseases as malignant neoplasm of trachea, bronchus, and lung. In 2017, 1.88 million mortality was likely two-time folds of colon and stomach cancer, called the first killer in carcinomas family for patients in the globe [1]. In the United States, lung and bronchus cancer is the first leading source of cancer death. The death rate was 38.5 [38.4, 38.6] under 95\% Confidence Interval (Cl) per 100,000 men and women per year based on 2014-2018 deaths of adjustedage in the U.S, reducing $5 \%$ of the death rate. There are $34.1 \%[33.8,34.4]$ of the death rate of $\mathrm{Cl}$ in Texas, reducing $4.6 \%$ of the death rate. Cancer statistics reported that the estimated new case of lung and bronchus cancer in 2021 in 235,760 cases, representing $12.4 \%$ of all new cancer cases, and estimated deaths are 131,880 cases, accounting for $21.7 \%$ of all cancer deaths [2-3]. Identifying related lung cancer factors will be beneficial to prevent from occurrence of lung cancer and improve patients' treatment with lung cancer.

Lung cancer incidence is directly relevant to the patient's lived ambiance. Underground miners' death from lung cancer was 2.36 times higher than the general population [4]. Smoking is widely recognized as the leading cause of lung cancer so that the effect of smoky coal exposure was higher for the risk of lung cancer [5]. Lung cancer is the result of lung infections and lesions for a long time, and lung infections are originated from fungal, viral, protozoal, and parasitic 
infections [6]. For instance, the COVID-19 virus is automatedly detected in lung infections [7]. Air spreading is one of the main routes of COVID-19 spreading. PM2.5 pollution led to a negative effect on human health and economic growth [8]. Thus, it is necessary to consider individual ecological footprint impacts on lung cancer research. The ecological footprint is an indicator of evaluation in environmental sustainability, including total ecological footprint, total biocapacity, ecological carbon footprint, ecological crop-land footprint, ecological fish-land footprint, ecological built-up land footprint, ecological grazing-land footprint, and ecological forest-land footprint. The ecological footprint is relatively related to human wellbeing [9-11]. Total bio-capacity (TBC), ecological crop-land footprints (ECL), ecological grazingland footprint (EGL), and ecological built-up land footprint (EBL) have significant positive influences on human subjective-welling beings, but ecological fish-land (EFL) has significant negative influences on SWB. Ecological carbon footprint (ECF) is significantly negatively related to SWB in developed countries [12].

Although the clinical impacts of lung cancer have been explored previously [13-15], the relationships between socioeconomic and environmental variables and lung cancer on a national scale have been never touched. Up to date, only four articles examined the national driving forces of lung cancer [16-19], all of which have assessed the effects of gender, age structure, religion, and race on the national wide lung cancer, while they neglected the roles of environmental factors on lung cancer. Therefore, it was urgent to explore possible contributions of social-economic, and environmental variables to global lung cancer mortality (LCM). Moreover, most of these studies used logistical regression to determine whether the odds ratio (OR) was beyond 1 or not [20], whereas they did not consider the space-time clusters with the lung cancer concentration. The spatial effects of socioeconomic and environmental factors on lung cancer during different historical periods should not be ignored because the countries worldwide have undergone divergent development progress during different historical periods. Additionally, these studies generally classified specific groups based on their gender and age, while they paid less attention to the globe or continent. Although the relationships of socioeconomic factors and covid-19 in the world have been clarified recently [21], the association between ecological footprint and lung cancer in the world is still unknown.

To fill these knowledge gaps, we developed an Artificial Neural Network (ANN) model and CRT Random Decision Tree algorithms (CRT-RDF) model to assess the global and regional contributions of socioeconomic and environmental impacts on lung cancer, respectively. The present study made potential contributions to the inherent knowledge. In this research, to begin with, we standardized 17 explanatory variables with social-economic, and environmental matrixes and performed ANN and CRT-RDF models. Secondly, through two different approaches, the common characteristic or determinants are revealed in the end.

\section{Data And Method}

\subsection{Data}

Ecological footprint data were captured from an open dataset published by the global ecological footprint network (https://www.footprintnetwork.org/). The dataset included a worldwide ecological footprint during 1961-2016. Global lung cancer data were collected from an open dataset published our world in data (https://ourworldindata.org/). The other factors (e.g., urbanization rate, education, health, happiness, and religion) are from the open dataset of the World Bank (https://data.worldbank.org/). Via the combination of three datasets, 94 countries were locked in this research, including 1097 observations during 2006-2016. When conducting two approaches, lung cancer death rate is classified into three-level from low to high as a unique dependent variable. Independent variables incorporate social-economic and environment two aspects, involving 16 explanatory variables in total. Social-economic impacts had 8 factors, which refers to education, stability, economic (per GDP), health, total population, urbanization rate, happiness, and religion aspect of Christian. Environmental impacts had 7 factors that contain EF consumption per capital (EF), carbon footprint 
(CBF), Cropland footprint (CLF), Forestland footprint (FLF), Bio-capacity (BC), Built-up land footprint (BLF), Fishing land footprint (FIF), Grazing-land footprint (GLF), as shown in supplement 1.

\subsection{Study Framework}

In this research, we firstly performed standardization of independent variables and classify dependent variables in 94 countries, then implemented spatial autocorrelation to detect lung cancer clusters. Furthermore, we repeatedly investigated the ANN model and CRT-RDF model until optimal models coming out. The study framework is in Figure.1.

\subsection{Study Area}

Despite ecological footprint in the world is computed in 187 countries and happiness index records 101 countries, 94 countries in Table 1 without missing data are left in this research. We used the death population in 94 countries to divide by total population as mortality rate, ranking three classes to represent $33 \%, 67 \%$, and $100 \%$ of lung cancer death from low to high. 1 in Figure 2 indicates the low level of lung cancer death in 54 countries. 2 in Figure 2 points to mediate the level of lung cancer death in eight countries. 3 in Figure 2 described the high level of lung cancer death in 32 countries.

Table 1 LCM Ranking

\begin{tabular}{|l|l|}
\hline Ranking & Country \\
& $\begin{array}{l}\text { Afghanistan, Angola, Azerbaijan, Bahrain, Benin, Bhutan, Bolivia, Botswana, Burkina Faso, Burundi, } \\
\text { Cameroon, Chad, Chile, Colombia, Congo, Costa Rica, Dominican Republic, El Salvador, Ethiopia, Ghana, } \\
\text { Haiti, Jordan, Kazakhstan, Kenya, Kuwait, Lebanon, Madagascar, Malawi, Malaysia, Mali, Mexico, } \\
\text { Myanmar, Nepal, Nicaragua, Niger, Panama, Paraguay, Peru, Rwanda, Saudi Arabia, Sierra Leone, } \\
\text { Singapore, Somalia, Sri Lanka, Tanzania, Togo, Tunisia, Uganda, United Arab Emirates, Uzbekistan, } \\
\text { Venezuela, Yemen, Zambia, Zimbabwe }\end{array}$ \\
& \\
& Albania, Armenia, Australia, Austria, Belarus, Israel, Lithuania, Luxembourg, Norway \\
& Portugal, Sweden, Switzerland \\
& $\begin{array}{l}\text { Argentina, Bangladesh, Belgium, Bosnia and Herzegovina, Brazil, Canada, China, Croatia, Czech Republic, } \\
\text { Denmark, Estonia, France, Germany, Greece, India, Indonesia, Italy, Japan, Latvia, Montenegro, } \\
\text { Netherlands, Pakistan, Philippines, Poland, Romania, Russia, Serbia, Slovenia, Spain, Thailand, Turkey, } \\
\text { United Kingdom, United States, Vietnam }\end{array}$ \\
\hline
\end{tabular}

2.4 Spatial autocorrelation

Spatial autocorrelation is a basic skill of spatial analysis [22]. It is defined as the dependence of a given variable's values on the values of the geographically weighted matrix at neighboring locations [23]. SAC is also called global Moran I. When it is positive, that means high values are associated with relatively high values at neighboring locations, conversely, it is negative, which means high values correspond to relatively low values at neighboring locations [24]. The presence of spatial autocorrelation is important, either because it is usually taken as indicating that there is something of interest in the distribution of map values that calls for further investigation in order to understand the reasons behind the observed spatial variation, or because the presence of spatial autocorrelation implies information redundancy and has important implications for the methodology of spatial data analysis [25]. Thus, Global Moran I reflect the association between the dependent variable and its spatial dependence.

\subsection{Artificial Neural Network Algorithm}

Artificial Neural Network is one of the available methods of machine learning. ANN has been shown superior to algorithmic methods in estimating environmental uncertainty due to its high generalization ability and accuracy [26]. A 
neural network model is considered as a directed graph with the implied properties, including: "A state variable $n_{i}$ is associated with each node $i, A$ real-valued weight $w_{i k}$ is associated with each connection (ik) between two nodes $i$ and $k$, $A$ real-valued bias vi is associated with each node $i, A$ transfer function $f_{i}\left[n_{k}, w_{i k}, v_{i},(i \neq k)\right]$ is defined for each node $i$, which determines the state of the node as a function composed of its bias, the weights of incoming connections, and the states of nodes connected to it. " [27-28].

\subsection{CRT Random Decision Tree regression}

Random Decision Forests have been shown to be effective in a wide range of classification and regression problems [29]. They consist of a set of binary trees, each stochastically trained on random subsets of the data. Despite any one tree may be overfitted, the randomness in the training process encourages the trees to give independent estimates, which can be combined to achieve an accurate and robust result. It runs efficiently on large databases. The advantages of CRTRDF are that it can handle thousands of input variables without variable deletion. Variable with high importance has a significant impact on the outcome values. In this research, the CRT-RDF model is performed in SPSS software.

\section{Results}

\subsection{The spatial-temporal variation of LCM}

In this paper, we chose inverse distance and Euclidean distance row to conduct spatial autocorrelation. The results include, global Moran of the LCM was 0.76, expected index was -0.01, the variance was 0.0027, z-score was 14.82 , and p-value was 0 . That means LCM exists positively significant spatial autocorrelation and is clustered. It also tells us that lung cancer outbreak is positively related to spatial neighboring lung cancer death. In Figure 3, LCM is classified into two clusters in terms of $\mathrm{HH}$ and LL. HH has distributed 2 countries Chad and Rwanda at the top of the map, and LL occupied 33 countries, including Angola, Azerbaijan, Bahrain, Belgium, Bosnia and Herzegovina, Brazil, Burkina Faso, Burundi, Canada, China, Colombia, Czech Republic, Denmark, El Salvador, France, Ghana, India, Jordan, Kazakhstan, Lithuania, Luxembourg, Montenegro, Myanmar, Nicaragua, Poland, Portugal, Romania, Saudi Arabia, Spain, Switzerland, Uganda, United Arab Emirates, United Kingdom the middle bottom of the map.

\subsection{Spatial-temporal Comparison of LCM}

During the study period of 2006-2016, concerning the number of total cases, China and the U.S are the two largest countries of LCM among ten countries in Figure 4. The mortality of lung cancer dramatically increased from 422144.6 to 685286.4 while the U.S increased from 174411.3 to 185121.1 within a decade. The lowest mortality was less than 7500 in South Africa, compared to other countries. Nevertheless, as far as increasing speed, China and India had the fastest growth rate of LCM that tended to two-time increased speed in a decade, based on Figure 5. The mortality in Italy displayed an inverse U-shape with a down-turn tendency, which is opposed to the going-up tendency in other eight countries. Interestingly, only had Russia negatively growth in ten countries, decreased $11 \%$ of mortality rate in a decade. Furthermore, Germany and Japan increased beyond 15\% whereas Canada, Italy, South Africa, and the U.S increased no more than 10\%. In Figure 5, U.K had the lowest increased speed of less than 5\%.

\subsection{ANN results}

We took advantage of Multilayer Perceptron Network to choose the standardized option for the Rescaling Method for Covariates. Figure 6 exhibited the ANN chart. We see one hidden layer in Figure 6 . The input layer on the left of Figure 6 consisted of 14 standardized independent variables. Output layer on the right comprised three classes of LCM. In table 2 , observed cases are divided into training cases of $70 \%$ and testing cases of $30 \%$. The predicted accuracy reached $97 \%$ regardless of training cases and test cases. Figure 7 further demonstrated predicted cluster distribution in the three 
levels. The dots of class 1 concentrated on $100 \%$ with blue color, rather than the dots of class 2 and class 3 . The dots on the second class in the middle of figure 5 were located at proximately $100 \%$ with red color, instead of the dots of the first class and the last lass. The dots in the third class were distributed at a high percent with green color.

Table 2 Predicted Accuracy

\begin{tabular}{|c|c|c|c|c|c|c|c|c|c|c|}
\hline \multirow[t]{2}{*}{ Sample } & \multirow[t]{2}{*}{ Observed } & \multicolumn{4}{|c|}{ Predicted with ANN } & & \multicolumn{4}{|c|}{ Predicted with CRT } \\
\hline & & 1 & 2 & 3 & $\begin{array}{l}\text { Percent } \\
\text { Correct }\end{array}$ & Observed & 1 & 2 & 3 & $\begin{array}{l}\text { Percent } \\
\text { Correct }\end{array}$ \\
\hline \multirow[t]{4}{*}{ Training } & 1 & 215 & 4 & 0 & $98.20 \%$ & 1 & 343 & 16 & 2 & $95.0 \%$ \\
\hline & 2 & 1 & 221 & 9 & $95.70 \%$ & 2 & 6 & 354 & 15 & $94.4 \%$ \\
\hline & 3 & 0 & 5 & 218 & $97.80 \%$ & 3 & 2 & 1 & 358 & $99.2 \%$ \\
\hline & $\begin{array}{l}\text { Overall } \\
\text { Percent }\end{array}$ & $32.10 \%$ & $34.20 \%$ & $33.70 \%$ & $97.20 \%$ & $\begin{array}{l}\text { Overall } \\
\text { Percent }\end{array}$ & $32.0 \%$ & $33.8 \%$ & $34.2 \%$ & $96.2 \%$ \\
\hline \multirow[t]{4}{*}{ Testing } & 1 & 138 & 3 & 1 & $97.20 \%$ & & & & & \\
\hline & 2 & 0 & 141 & 3 & $97.90 \%$ & & & & & \\
\hline & 3 & 1 & 1 & 136 & $98.60 \%$ & & & & & \\
\hline & $\begin{array}{l}\text { Overall } \\
\text { Percent }\end{array}$ & $32.80 \%$ & $34.20 \%$ & $33.00 \%$ & $97.90 \%$ & & & & & \\
\hline
\end{tabular}

Table 4 described the importance of independent variables in this research. The most important variable was the education index, taking up $100 \%$, indicating education degrees were closely related to lung cancer. That means people with high education have a low occurrence of lung cancer, otherwise, those who had low education exposure on high risk of lung cancer. The second significant variable was ecological carbon footprint with $74.4 \%$, meaning carbon emission directly impacts lung cancer rise. At the same time, carbon consumption is crucial in improving environmental quality. Health and GDP after carbon footprint account for $67 \%$ of important effects, which point out economic development and health positive impacts on LCM. Notably, the health index is defined by life expectancy, which is easy to think that high aging has a high risk of lung cancer. Lastly, ecological grazing-land footprint, total population, and ecological crop-land footprint also contributed to LCM. Unsurprisingly, the population increased more resulted in a high risk of lung cancer such as China. This explained why China took stringent quarantine policy in the pandemic.

Table 3 The Comparison of Independent Variable Importance 


\begin{tabular}{|c|c|c|c|c|c|}
\hline \multirow[t]{2}{*}{ Independent Variable } & \multirow[b]{2}{*}{ No. } & \multicolumn{2}{|l|}{ ANN Method } & \multicolumn{2}{|c|}{ CRT-RDF Method } \\
\hline & & Importance & Normalized Importance & Importance & Normalized Importance \\
\hline Zscore(CBF) & 1 & 0.098 & $74.4 \%$ & 0.383 & $100.0 \%$ \\
\hline Zscore(education) & 2 & 0.131 & $100.0 \%$ & 0.343 & $89.4 \%$ \\
\hline Zscore(pergdp) & 3 & 0.089 & $67.8 \%$ & 0.326 & $85.0 \%$ \\
\hline Zscore(health) & 4 & 0.089 & $67.5 \%$ & 0.323 & $84.1 \%$ \\
\hline Zscore(EF) & 5 & 0.041 & $18.9 \%$ & 0.319 & $83.1 \%$ \\
\hline Zscore(CLF) & 6 & 0.078 & $59.3 \%$ & 0.265 & $69.2 \%$ \\
\hline Zscore(SWB) & 7 & 0.029 & $22.3 \%$ & 0.198 & $51.7 \%$ \\
\hline Zscore(FLF) & 8 & 0.064 & $48.6 \%$ & 0.194 & $50.6 \%$ \\
\hline Zscore(stability) & 9 & 0.054 & $41.3 \%$ & 0.174 & $45.3 \%$ \\
\hline Zscore(BC) & 10 & 0.044 & $20.1 \%$ & 0.148 & $38.6 \%$ \\
\hline Zscore(TP) & 11 & 0.083 & $63.0 \%$ & 0.137 & $35.6 \%$ \\
\hline Zscore(BLF) & 12 & 0.060 & $45.7 \%$ & 0.124 & $32.3 \%$ \\
\hline Zscore(FIF) & 13 & 0.071 & $54.2 \%$ & 0.122 & $31.9 \%$ \\
\hline Zscore(URB) & 14 & 0.028 & $12.8 \%$ & 0.108 & $28.1 \%$ \\
\hline Zscore(GLF) & 15 & 0.086 & $65.7 \%$ & 0.103 & $26.9 \%$ \\
\hline Zscore(Christian) & 16 & 0.067 & $51.3 \%$ & 0.100 & $26.1 \%$ \\
\hline
\end{tabular}

\subsection{CRT-CRT-RDF results}

In this research, classification and Regression Trees (CRT) is used to perform CRT-RDF methods. CRT mainly present associations between variables via hierarchical and graphical tree structures [30]. In figure 8 , the maximum tree depth was 5 , minimum cases in parent node were 10, minimum cases in child node were 5 . We got 35 nodes, 18 terminal nodes, 5 depths of the tree, 0.038 estimated risk, and 0.006 Std. error. The predicted percentage of three levels of LCM was $95 \%, 94.4 \%, 99.2 \%$, respectively. The overall percentage was $96.2 \%$. The tree structure of LCM in figure 8 broke down education in two parts of 662 cases and 435 cases. Class 3 of LCM is the most severe part of the three classes. It derives from the ecological carbon footprint that depends on the urbanization of each country. Urbanization ascribes from ecological forestland shrinking on a large scale. Class 1 of LCM relied on total bio-capacity, which was from less than 0.51 ecological built-up land footprints that were generated by more than -0.37 total ecological footprints. Class 2 of LCM originated from less than 0.07 GDP, which was contributed by beyond -1.2 ecological crop-land footprints that were produced by no more than 6.94 total population. Thus, the root of LCM is deforestation that impacts ecological imbalance.

The prediction of the accuracy of LCM in the CRT-CRT-RDF model is beyond $96 \%$ in table 2 . Table 3 described the importance of independent variables in the CRT-RDF method. The most important variable was carbon footprint, taking up $100 \%$, articulating carbon release is the primary factor in the detection of LCM. The second significant variable was the education index, accounting for $89.4 \%$, expressing education levels were relatively link to LCM, just like the scenario of the ANN method. Health and GDP after education index account for $84.1 \%$ and $85 \%$ of important effects, which is the 
same as the ANN method. Remarkably, the total ecological footprint occupied $83.1 \%$, instead of $18.9 \%$ in the ANN method in Table 3, portraying total ecological footprint played a vital role in the generation of LCM. What is more, ecological crop-land footprint and ecological forest footprint had the same contribution as the ANN approach. Finally, ecological grazing-land footprint, total population, and Christian impacts were decreased in the CRT-RDF method. The distinction in the CRT-RDF was that population dedicated health and GDP while ecological grazing-land is the reason for carbon footprint increasing in figure 8.

\section{Discussion}

Everything is health and health is everything in the theory of social determinants of health (SDOH) [31]. Health is a product of vulnerability, being subjected to multi-dimensional change, such as the environment, food security, race, gender, economy, education, geography [32].

\subsection{Social factor Impacts}

In this research, we focused on social factor impacts on LCM, involving education, health, happiness, and urbanization four aspects. First, education is overweight by $90 \%$ impact factor regardless of the ANN model or the CRT-CRT-RDF model. This is a breakthrough. Although previous studies reported that income and education are likely to contribute to disparities in non-small cell lung cancer, education interventions mainly pay attention to training health workers, community health service organizations that provide valued information or services to increase lung cancer screening benefits and shrinking lung cancer stigma [33]. Second, health and happiness are linked to mitigate lung cancer suffering and improve patients' life quality physically and mentally. Sunwha et al. (2021) took a view that lung cancer stigma had a negative impact on resilience and happiness so that encouraging patients with non-judgmental methods is beneficial to increase the happiness of individuals with advanced cancer [34]. Health is linked to lung cancer due to a high-quality diet. Myneni et al. proposed (2021) a high-quality diet was inversely associated with lung cancer of the squamous cell subtype [35]. Lastly, urbanization is the least factor in conducting lung cancer investigations. Lower urbanization produced either decreasing mortality or increased mortality. In the U.S, lung cancer incidence rate during 2007-2016 was detected in both urban and rural areas [36-37].

\subsection{Demographical and Political Factor Impacts}

Total population contribution fluctuates as a result of $63 \%$ importance in the ANN model but $35.6 \%$ importance in the CRT-RDC model. In other words, a demographical factor is not directly correlated with LCM, instead, it indirectly is associated with economic development that contributes to LCM via ecological crop-land footprint and health in figure 8. Qian et al. (2020) advanced Age 50-79 years, black race, and history of radiotherapy were more exposed high risk for second primary lung cancer than another disease in patients [38]. Demographical Disparity, therefore, is not an ignorable factor that determines the appearance of other reasons in lung cancer research. Stability took up about $45 \%$ importance in the two methods, which means it is stable, but not important. In our research, political stability has not affected LCM and its related factors in figure 8. As matter of fact, the politics of pollution such as media interest, provoke public disquiet and unease, aggravating social contradiction, indirectly dedicating public health [39].

\subsection{Economic and religious factor Impacts}

GDP is an indicator of economic development. In our research, GDP presented a compelling performance in both methods. In the ANN method, GDP attained $67.8 \%$ importance. At the same time, GDP is suitable as the third contributor in the CRT-CRT-RDF approach. GDP, as node 4 in figure 8, directly influenced LCM. GDP contribution on lung cancer also was documented well in many journals. For example, higher health spending was significantly associated with higher cancer survival value, which leads to the state-level health disparities in the United States [40]. Christian is worthy of 
skepticism due to slothful performance in the two regressions. It triggered $51.3 \%$ significance in the ANN model and $26.1 \%$ importance in the CRT-CRT-RDF model for LCM. We chose Christianity as an explanatory variable to probe whether religion objectively helps patients with lung cancer improve happiness at the end of their lifetime. There are no roles in religion on the decision tree. Religion, as the actor of spirituality in emotion regulation, was studied imperfectly up to now. Thus, it is possible to debate if it helps cancer patients to adjust to their disease and achieve higher well-being [41].

\subsection{Environmental factor Impacts}

Undoubtedly, environmental factors impact LCM increasing based on our search. Ecological carbon footprint performed key positions in both methods. It took up $74.4 \%$ importance, located the number two ranking in the ANN model, yet it has $100 \%$ importance, standing out the top one ranking in the CRT-CRT-RDF model, directly affecting LCM. It is also verified in health issues. For example, black carbon, act as a carrier for highly toxic and carcinogenic polycyclic aromatic hydrocarbons in air, water, and soil, bringing about severe health impairment [42]. Total ecological footprint, ecological forest-land footprint, and ecological grazing-land footprint are the reasons for carbon discharge in figure 8. Especially, persistent organic pollutants (POPs) directly increased the risk of lung cancer using pre-diagnostic serum samples in a case-cohort study based on a population-based prospective cohort [43]. Furthermore, land Transportation generated the greatest impact on ozone respiratory mortality, including lung cancer [44]. That is why ozone and fine particulate matter (PM2.5) exposure was well concerned by environmentalists. Albeit Environmental exposure is intangible, adverse health effects are irretrievable. Thus, environmental sustainability should be the top priority in human sustainable development. In addition, ecological crop-land footprint, ecological built-up land footprint, ecological fish-land footprint, and ecological grazing-land footprint have different great impacts on LCM. Those factors are supported each other, ultimately, the chain reaction between factors will be irreversible, causing permanent damage for humans.

Using pooled panel data of LCM, ecological footprint observations, and social-economic statistics at the cross-national level in the world from 2006 to 2016, we applied spatial autocorrelation and spatial-temporal models to examine socialeconomic and environmental effects of three classes of LCM from low to a high level. The results made a point that China had a high risk of LCM regardless of total amounts or dynamic growth speed, therein China implemented stringent People's Republic of China law on the prevention and treatment of infectious disease [45]. This research provided strong evidence why China put in place various strict measures to suppress the resurgence of the epidemic [46]. COVID-19 cases in China also verified the effectiveness of controlling the spread of the deadly virus. At the same time, LCM in other countries increasing, even outbreak of COVID-19 and Delta mutation, is sufficient to demonstrate that controlling virus expansion and reducing LCM should be taken uncompromising quarantine measures before eradicating the virus.

The ANN model elucidated education and ecological carbon footprint were two overarching factors of LCM. At the same time, the outcomes in the CRT-CRT-RDF model described that hierarchical LCM stems from three various factors. The ecological forestland footprint played a significant and positive role in curbing carbon emission, which directly stimulates an increase in LCM in the most severe countries of lung cancer. The total ecological footprint contributed to education impacts, which caused lung cancer in low-level countries. The total population affected on education factors that leads to lung cancer in middle countries of LCM. Thus, the conservation of forestland is imperative. Certain spatial spillover mechanisms may function to prevent deforestation [47].

\section{Conclusion}

The spatial-temporal analysis of LCM is powerful skill to capture sensitive clusters. Instead, the application in the global area is rare. ANN model and CRT-CRT-RDF model in the application of LCM are novel for pinpointing etiology and pathogenesis on LCM. Overfitting in the CRT-CRT-RDF model might be existed so as to generate different outcomes. Models are lack of stability and validation in context of changing different spectrums. 


\section{Declarations}

Author Contributions: Conceptualization and methodology, X.W. and J.Z.; investigation, resources, and data curation, X.W.; writing-original draft preparation, X.W.; writing, reviewing, and editing, J.Z., and B.B.D.; supervision and project administration, B.B.D.: reviewing, writing, and editing. All authors have read and agreed to the published version of the manuscript.

Funding: This research received no external funding.

Institutional Review Board Statement: Not applicable.

Informed Consent Statement: Not applicable.

Data Availability Statement: All data, models, and code generated or used during the study appear in the submitted article.

Conflicts of Interest: The authors declare no conflict of interest.

Consent for publication: Not applicable.

\section{References}

1. https://ourworldindata.org/cancer

2. Shen MJ, Xu Z, Jiang K, Xu W, Chen Y, Xu Z. Long noncoding nature Brain-Derived neurotrophic factor antisense is associated with poor prognosis and functional regulation in Non-Small cell lung cancer. Tumor Biology. 39(5). doi:10.1177/1010428317695948

3. https://seer.cancer.gov/statfacts/html/lungb.html

4. Kreuzer M, Deffner V, Schnelzer M, Fenske N. Mortality in Underground Miners in a Former Uranium Ore Mine: Results of a Cohort Study Among Former Employees of Wismut AG in Saxony and Thuringia. Deutsches Aerzteblatt International. 2021;118(4):41-48. doi:10.3238/arztebl.m2021.0001

5. Bonner MR, Rothman N, Mumford JL, et al. Green tea consumption, genetic susceptibility, PAH-rich smoky coal, and the risk of lung cancer. MutRes-Genetic Toxicology and Environmental Mutagenesis. 2005;582(1):53-60. doi:10.1016/j.mrgentox.2004.12.008

6. Schub, T. B., \& Holle, M. R. B. O. (2017). Lung Cancer: Complications - Infection. CINAHL Nursing Guide.

7. Ranjbarzadeh R, Jafarzadeh Ghoushchi S, Bendechache M, et al. Lung Infection Segmentation for COVID-19 Pneumonia Based on a Cascade Convolutional Network from CT Images. BioMed Research International. April 2021:1-16. doi:10.1155/2021/5544742

8. Fu Z, Li R. The contributions of socioeconomic indicators to global PM2.5 based on the hybrid method of the spatial econometric model and geographical and temporal weighted regression. Science of the Total Environment. 2020;703. doi:10.1016/j.scitotenv.2019.135481

9. Dietz, Thomas, Rosa, Eugene A., York, Richard, 2009. Environmentally efficient well-being: rethinking sustainability as the relationship between human well-being and environmental impacts. Human Ecology Review 16 (1), 114-123.

10. Evans, G. F., and E. Z. Soliman. 2019. Happier countries, longer lives: an ecological study on the relationship between subjective sense of well-being and life expectancy. Global Health Promotion 26 (2):36-40.

11. Easterlin, Richard, Sawangfa, Onnicha, 2009. Happiness and economic growth: does the cross-section predict time trends? Evidence from developing countries. In: Diener, Ed, Helliwell, John F., Kahneman, Daniel (Eds.), International 
Differences in Well-Being. Oxford University Press, New York, NY, pp. 166-216.

12. Zhang J, Zhan FB, Wu X, Zhang D. Partial Correlation Analysis of Association between Subjective Well-Being and Ecological Footprint. SUSTAINABILITY. 2021;13(3):1033. doi:10.3390/su13031033

13. Yingxian DONG, Daojun ZHU, Guowei CHE, et al. Clinical Effect of Day Surgery in Patients with Lung Cancer by Optimize Operating Process. Chinese Journal of Lung Cancer. 2020;23(2):77-83. doi:10.3779/j.issn.10093419.2020.02.02

14. Shang Y, Zang A, Li J, et al. MicroRNA-383 is a tumor suppressor and potential prognostic biomarker in human nonsmall cell lung cancer. Biomedicine \& Pharmacotherapy. 2016;83:1175-1181. doi:10.1016/j.biopha.2016.08.006

15. Ningning DING, Yousheng MAO. Advances in Lymph Node Metastasis and the Modes of Lymph Node Dissection in Early Stage Non-small Cell Lung Cancer. Chinese Journal of Lung Cancer. 2016;19(6):359-363. doi:10.3779/j.issn.1009-3419.2016.06.12

16. Bo Cheng, Cong Wang, Bing Zou, et al. A nomogram to predict outcomes of lung cancer patients after pneumonectomy based on 47 indicators. Cancer Medicine. 2020;9(4):1430-1440. doi:10.1002/cam4.2805

17. Felip E. El cáncer de pulmón en mujeres. Arbor: Ciencia, Pensamiento y Cultura. 2015;191(773):a235. doi:10.3989/arbor.2015.773n3005

18. Timmermann, C. (2014). A History of Lung Cancer: The Recalcitrant Disease. Studies in History and Philosophy of Biological and Biomedical Sciences, 48, 122-125.

19. Jussawalla, D., Jain, D. Lung cancer in Greater Bombay: correlations with religion and smoking habits.Br J Cancer40, 437-448 (1979). https://doi.org/10.1038/bjc.1979.199

20. Sun X, Dai X, Shi Y, Lin Y. [A case-control study on the relationship among indoor air pollution, depression, and oncogenesis of lung cancer]. Zhongguo Fei ai za Zhi = Chinese journal of lung cancer. 2002;5(2):101-103. doi:10.3779/j.issn.1009-3419.2002.02.07

21. Kutela B, Novat N, Langa N. Exploring the geographical distribution of transportation research themes related to COVID-19 using a text network approach. Sustainable Cities and Society. 2021;67. doi:10.1016/j.scs.2021.102729

22. Getis A. A history of the concept of spatial autocorrelation: a geographer's perspective,Geogr Anal, 2008, vol. 40(pg. 297-309)

23. Cliff AD, Ord JK., Spatial autocorrelation, 1973 London Pion.

24. Griffith, D. (2016). Spatial autocorrelation. Oxford University Press.

25. Cressie N 1991 Statistics for Spatial Data. Wiley, New York 14767 Spatial Autocorrelation Dacey M 1965 A review of measures of contiguity for two and color maps. In: Berry B, Marble D (eds.) Spatial Analysis: A Reader in Statistical Geography. Englewood Cliffs, NJ, pp. 479-95

26. Ablameyko, S. (2003). Neural networks for instrumentation, measurement, and related industrial applications. IOS.

27. B. Muller, J. ReinhaCRT-RDF, M.T. Strickland, Neural Networks an Introduction, Springer-Verlag Berlin Heidelberg, 1995.

28. 28. Erkam, G. \& Gulgun, K. (2011). Definition of artificial neural networks with comparison to other networks. Procedia Computer Science. Volume 3, Pages 426-433 https://doi.org/10.1016/j.procs.2010.12.071

29. Breiman, L.: Random forests. Machine Learning 45, 5-32 (2001)

30. Machuca, C., Vettore, M.V., Krasuska, M. et al. Using classification and regression tree modeling to investigate response shift patterns in dentine hypersensitivity. BMC Med Res Methodo/17, 120 (2017).

https://doi.org/10.1186/s12874-017-0396-3

Page $11 / 18$ 
31. Laverack G. Health activism: the way forward to improve health in difficult times. Global health promotion. 2013;20(3):49-52. doi:10.1177/1757975913499038

32. English, L. M. (2012). Adult education and health. University of Toronto Press.

33. Castro S, Sosa E, Lozano V, et al. The impact of income and education on lung cancer screening utilization, eligibility, and outcomes: a narrative review of socioeconomic disparities in lung cancer screening. JOURNAL OF THORACIC DISEASE. 2021;13(6):3745-3757. doi:10.21037/jtd-20-3281

34. Cho S, Ryu E. The mediating effect of resilience on the happiness of advanced lung cancer patients. Supportive Care in Cancer. 2021:1. doi:10.1007/s00520-021-06201-0

35. Myneni, A. A., Giovino, G. A., Millen, A. E., LaMonte, M. J., Wactawski-Wende, J., Neuhouser, M. L., Zhao, J., Shikany, J. M., \& Mu, L. (2021). Indices of Diet Quality and Risk of Lung Cancer in the Women's Health Initiative Observational Study. Journal of Nutrition, 151(6), 1618-1627.

36. O’Neil, M.E.; Henley, S.J.; Rohan, E.A.; Ellington, T.D.; Gallaway, M.S. Lung Cancer Incidence in Nonmetropolitan and Metropolitan Counties-United States, 2007-2016. MMWR. Morb. Mortal. Wkly. Rep. 2019.

37. Gariazzo C, Binazzi A, Alfò M, Massari S, Stafoggia M, Marinaccio A. Predictors of lung cancer risk: an ecological study using mortality and environmental data by municipalities in Italy. International Journal of Environmental Research and Public Health. 2021;18(4). doi:https://www.mdpi.com/1660-4601/18/4/1896

38. Qian, Chengyuan, Hong Liu, Yan Feng, Shenglan Meng, Dong Wang, Mao Nie, and Mingfang Xu. 2020. “Clinical Characteristics and Risk of Second Primary Lung Cancer after Cervical Cancer: A Population-Based Study." PLoS ONE15 (8): 1-13. doi:10.1371/journal.pone.0231807.

39. Phillimore, Peter, et al. "Part II: Denaturalising Risk Politics: 'Industry Causes Lung Cancer': Would You Be Happy with That Headline?" Environmental Risks \& the Media, Nov. 1999, pp. 105-116. EBSCOhost, search-ebscohostcom.libproxy.txstate.edu/login.aspx?direct=true\&db=edo\&AN=17441979\&site=eds-live\&scope=site.

40. Yu-Che Lee, Rafael A. Calderon-Candelario, Gregory E. Holt, Michael A. Campos, Mehdi Mirsaeidi. State-Level Disparity in Lung Cancer Survival in the United States. Frontiers in Oncology. 2020;10.

doi:10.3389/fonc. 2020.01449

41. Kouloulias, V., Kokakis, J., Kelekis, N., Kouvaris, J., Kouloulias, V., Kokakis, J., Kelekis, N., \& Kouvaris, J. (2017). Global Quality of Life Scale. [Subscale from Questionnaire for Cancer Patients Regarding Religiosity]. Journal of Religion and Health, 56, 1137-1154.

42. Ali MU, Siyi L, Yousaf B, et al. Emission sources and a full spectrum of health impacts of black carbon associated polycyclic aromatic hydrocarbons (PAHs) in an urban environment: A review. Critical Reviews in Environmental Science \& Technology. 2021;51(9):857-896. doi:10.1080/10643389.2020.1738854

43. Park EY( 1 ), Park E( 1 ), Kim J( 1 ), et al. Impact of environmental exposure to persistent organic pollutants on lung cancer risk. Environment International. 143. doi:10.1016/j.envint.2020.105925

44. Silva RA, Adelman Z, Fry *, Meridith M., West JJ. The Impact of Individual Anthropogenic Emissions Sectors on the Global Burden of Human Mortality due to Ambient Air Pollution. Environmental Health Perspectives.

2016;124(11):1776-1784. doi:10.1289/EHP177

45. Wang ZJ. Law in crisis: a critical analysis of the role of law in China's fight against COVID-19. Griffith Law Review. 2020;29(2):253-272. doi:10.1080/10383441.2020.1790332

46. Yu X, Li N, Dong Y. Observation on China's Strategies to Prevent the Resurgence of the COVID-19 Epidemic. Risk management and healthcare policy. 2021;14:2011-2019. doi:10.2147/RMHP.S305413

47. Chen H, Shao L, Zhao M, Zhang X, Zhang D. Grassland conservation programs, vegetation rehabilitation and spatial dependency in Inner Mongolia, China. Land Use Policy. 2017;64:429-439. doi:10.1016/j.landusepol.2017.03.018

Page 12/18 


\section{Figures}

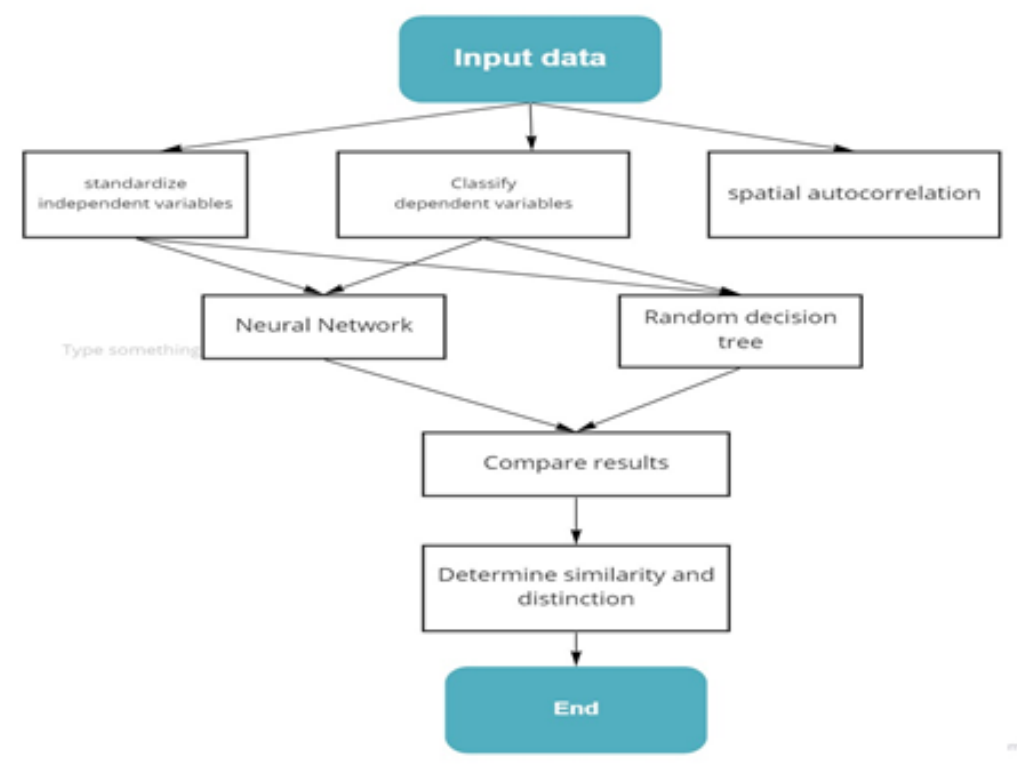

Figure 1

Study Framework

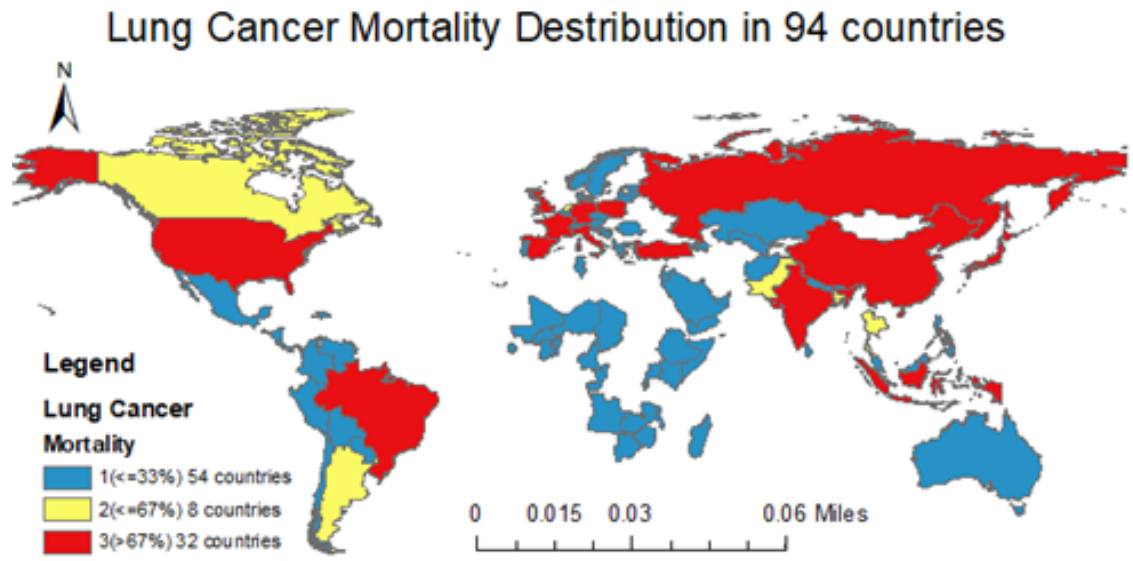

Figure 2

LCM Distribution in 94 countries 


\section{Lung Cancer Death spatial autocorelation Map in 94 countries}

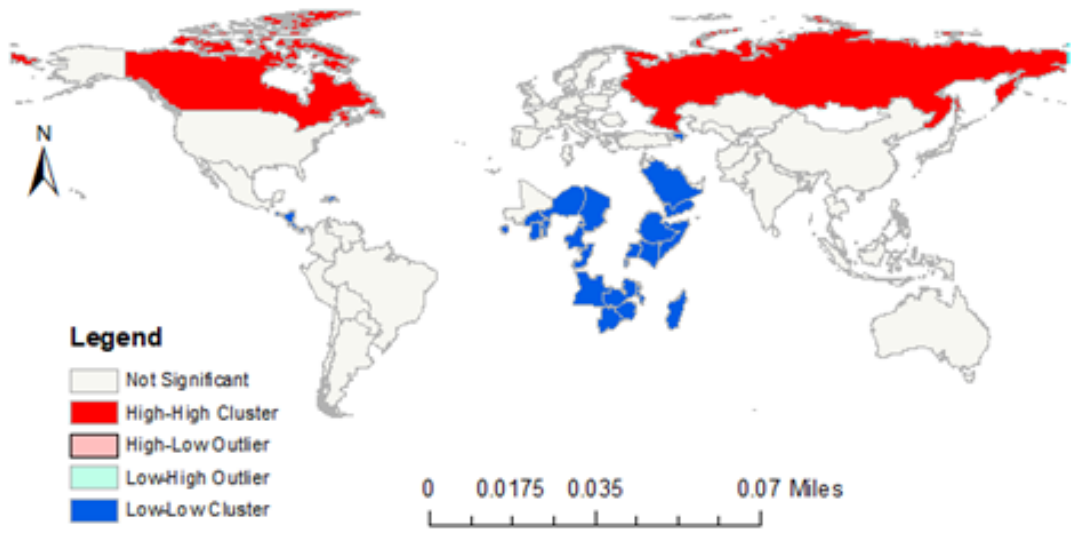

\section{Figure 3}

Spatial autocorrelation of LCM

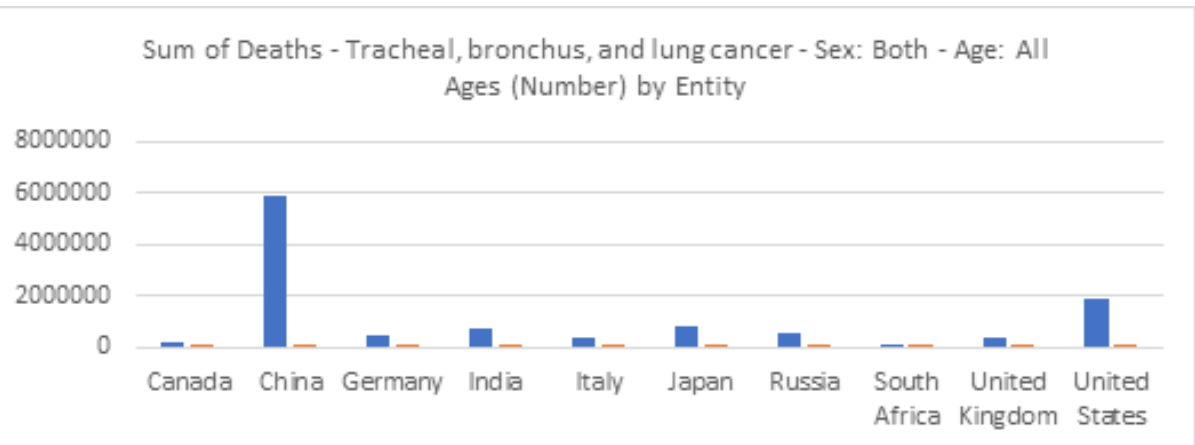

Figure 4

Cross-sectional Comparison of LCM
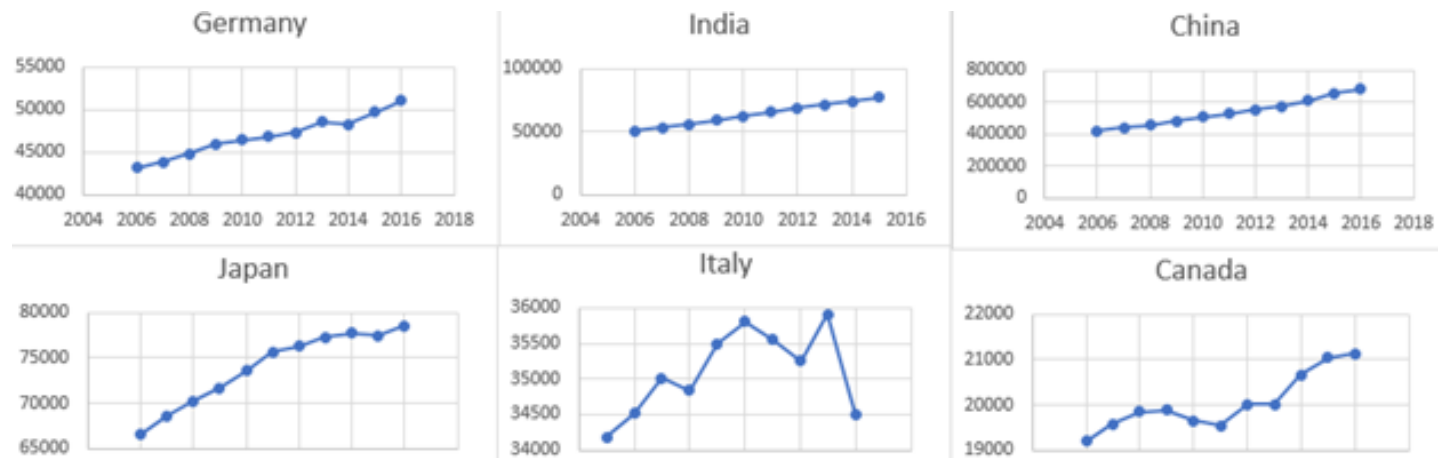

$\begin{array}{lllllll}2004 & 2006 \quad 2008 \quad 2010 \quad 2012 & 2014 & 2016 \quad 2018\end{array}$
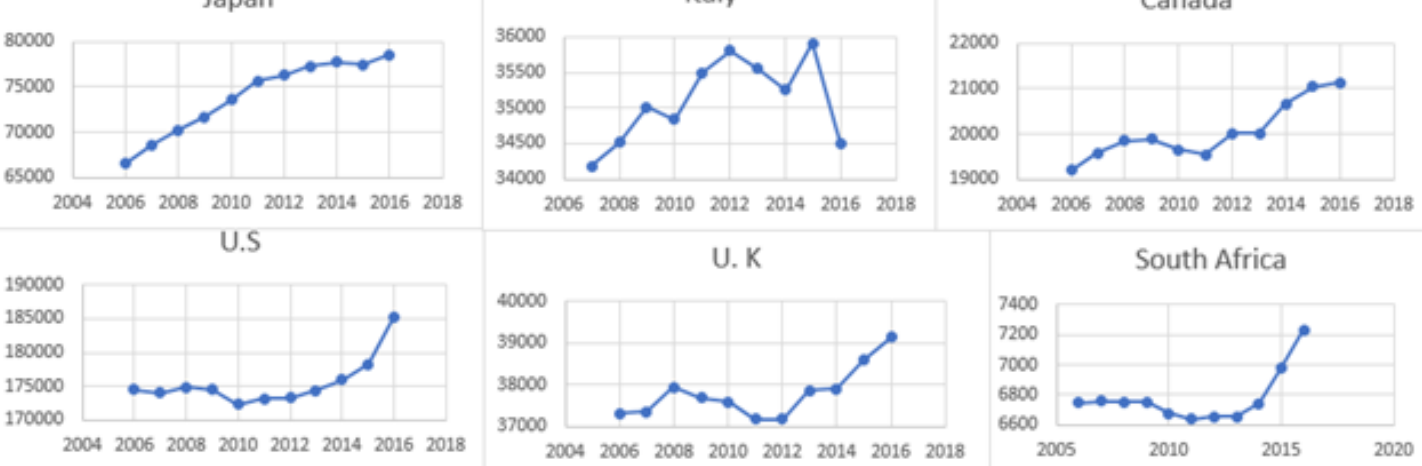


\section{Figure 5}

Longitudinal Comparison of LCM

- Synaptic Weight $>0$
Synaptic Weight $<0$

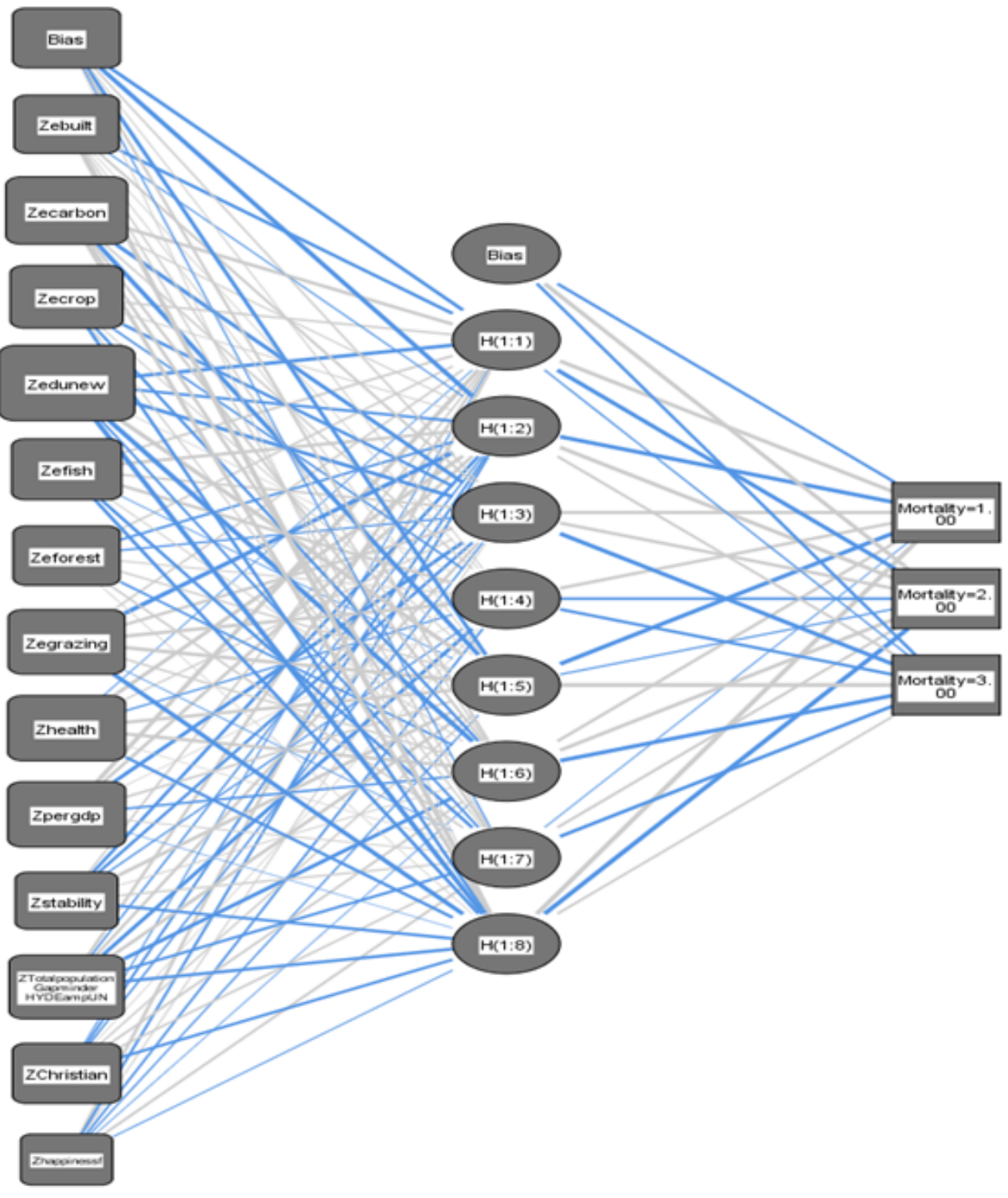

Hidden layer activation function: Hyperbolic tangent Output layer activation function: Softmax

\section{Figure 6}

ANN chart 


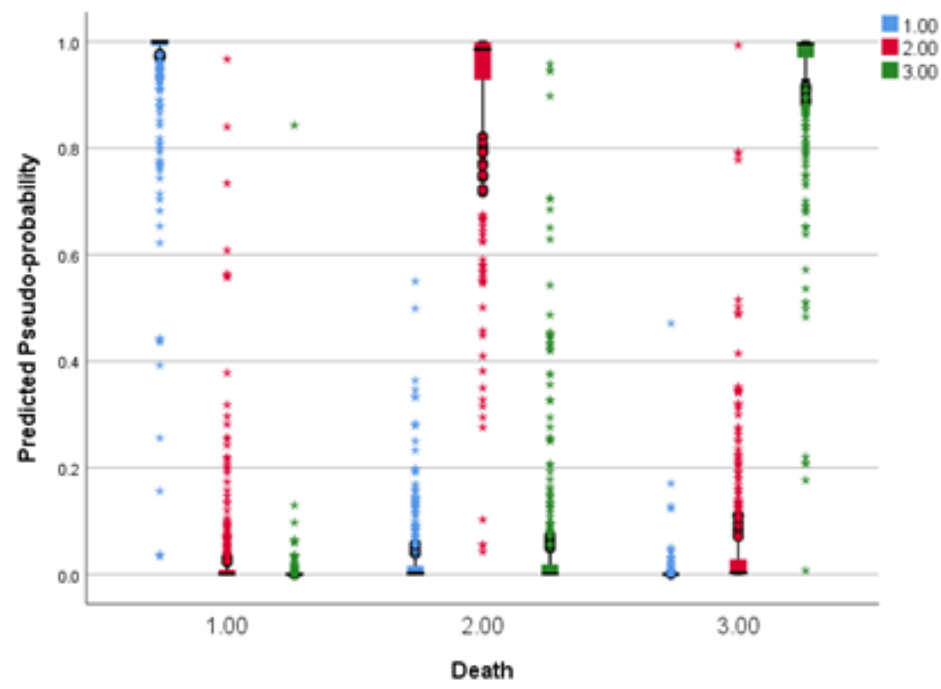

Figure 7

Predicted Pseudo-probability Chart 


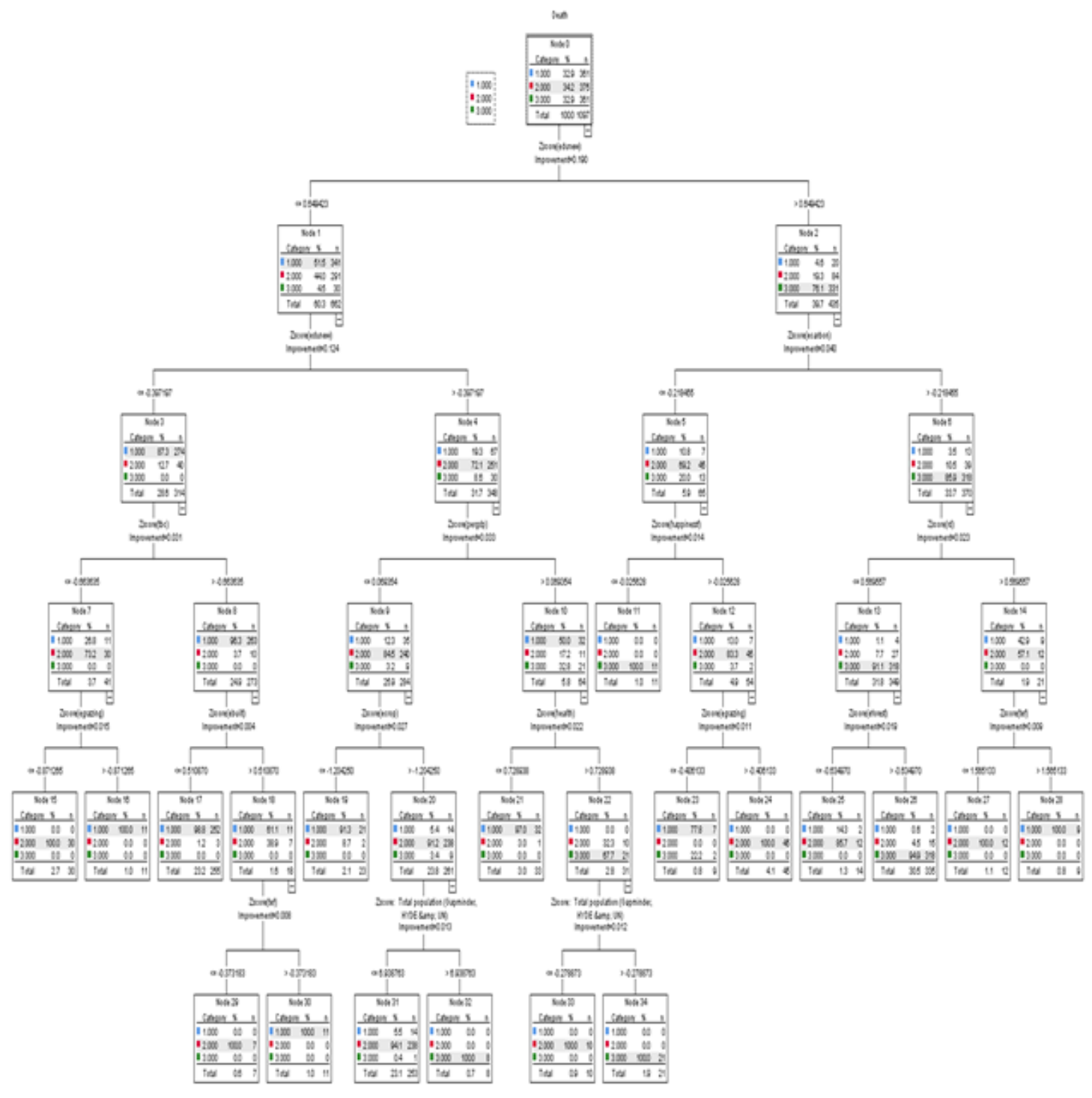

Figure 8

CRT-CRT-RDF Tree 


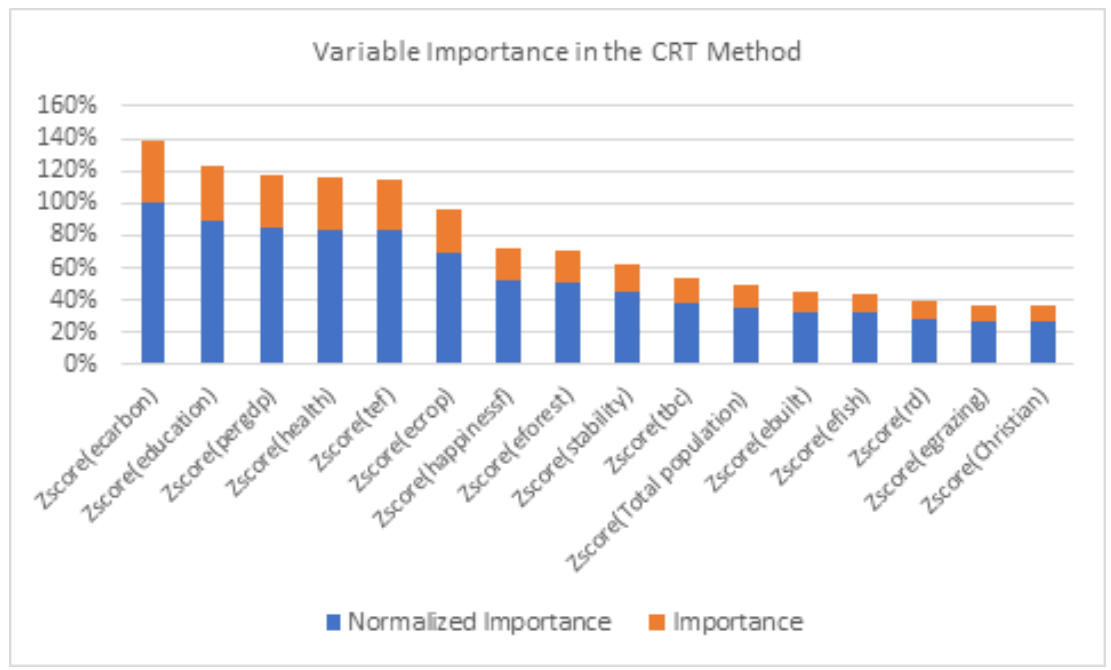

Figure 9

The Bar Chart of Variable importance

\section{Supplementary Files}

This is a list of supplementary files associated with this preprint. Click to download.

- Supplement1.docx 